\title{
ROBUST SPEED AND PARAMETER ESTIMATION FOR HIGH PERFORMANCE FIELD-ORIENTED CONTROL OF INDUCTION MOTOR DRIVES
}

\author{
Yehia S. Mohamed \\ Electrical Engineering Department, Faculty of Engineering, El-Minia \\ University, El-Minia Egypt
}

(Received November 23, 2009 Accepted December 28, 2009).

\begin{abstract}
This paper presents linear estimation techniques used to identify the stator resistance, the stator leakage inductance (transient inductance), the stator self inductance and rotor time constant of an induction motor without measuring its speed. Such estimation is important to achieve high performance for sensorless field-oriented control of induction motor drives. The discrete-time parameter estimation models express the relationships of the dynamic machine model in terms of measurable stator voltages, currents and an estimated motor speed. These models are represented by linear regression equations from which machine parameter vectors can be obtained using a recursive least squares (RLS) estimation algorithm. Moreover, a robust speed estimator based on a model-reference adaptive system (MRAS) is proposed to use the estimated parameters for accurate estimation of motor speed. The estimated motor speed is used iteratively in the parameters linear estimation models and is fed back in a sensorless field-oriented control of motor drive. The accuracy of parameter estimation is good regardless of load conditions. Simulation results validate the proposed scheme with reasonable accuracy of the estimated parameters as well as excellent performance of the motor drive.
\end{abstract}

\section{1- INTODUCTION}

Parameter and speed estimation are indispensable to the design of high performance induction motor drives. This fact is quite noticeable when the drive control scheme is based on the field-oriented control. Several different configurations are suggested for the field oriented-control according to the flux positioning method. Among them, the indirect field-oriented (IFO) control is known as an attractive candidate due to its simple structure and effective decoupling characteristics [1].

In the indirect vector control method, the calculation of slip-speed depends on the rotor time-constant, which changes significantly with rotor temperature when saturation is neglected. An error in the slip-speed calculation gives an error in the rotor flux position, resulting in improper coupling between the flux-and torque-producing current components due to axis-misalignment. This results in a torque response with possible overshoot or undershoot and a steady-state error. Therefore, in order to get the rotor flux positioned correctly, the accurate rotor circuit parameters are necessary. When incorrect parameter values are used in the controller, it may cause instantaneous errors in both torque and flux resulting in sluggish dynamics. Thus, it is essential to 
have accurate parameters of the induction machine in order to achieve the ideal instantaneous torque control [1] and [2].

Traditionally, machine parameters have been determined by performing noload testes and locked rotor tests. These experiments are not convenient because they require a human operator for electrical measurements and for intervention on the machine. The machine service must be interrupted while the tests are performed. This is in addition to the difficulty to perform the locked rotor tests on large power machines [3]. Moreover, the locked rotor test gives a very high slip frequency, which increases the skin-effect influence on the rotor resistance. Thus, they can lead to inadequate operating conditions and inaccurate parameter estimation. In [4] a review of numerous methods being proposed to identify the motor parameters is introduced. In most of these methods, only one parameter (rotor time constant or resistance) estimation is considered.

The use of parameter estimation techniques in the characterization of an induction machine has been reported by many research teams [5]-[10]. The main problems associated with these techniques are: 1) the use of special test signals [5], [7] and [9]; 2) the requirement of special operating conditions, such as to keep the machine at standstill [9]; and 3) the need of several operating points when the machine is supplied with sinusoidal pulse width modulated (PWM) waveforms [10].

On the other hand, speed sensorless IFO control of induction motor drives is recently receiving wide attention in the literature due to their low cost and high reliability. Among the various approaches that have been proposed, the observer-based [11]-[17] and the model-reference-adaptive-system (MRAS)-based [11], [17] and [20] speed estimators seem the most promising ones. In addition to an estimate of the mechanical speed, both the observer-based and the MRAS-based schemes provide a flux estimate which can be used in field-oriented control of the induction motor drive.

The observer-based estimators [12]-[16] have the advantages of removing the open-loop integration and providing a mechanism to include stator resistance estimation [12] and [13]. Among the observer-based methods, the extended Kalman filter [15], [16] and the adaptive observer [12]-[15] and [16] can be distinguished. Kalman filters are known for obtaining highly accurate estimates of state variables under noisy conditions, however, at the expense of large computation time requirements.

While the MRAS based estimators are preferred because of their simplicity, ease of implementation, and their proven stability [20]. They have a certain disadvantage in the low-speed area, where open-loop integration may lead to instability due to stator resistance and leakage inductance as well as rotor circuit parameters. All of this has limited the application of speed sensorless IFO controlled induction motor drives.

This paper presents models and procedures used to estimate most of electrical parameters of an induction motor. These parameters are namely, the stator resistance, the stator leakage inductance, the stator self inductance and rotor time constant. Such parameters are important for high performance speed sensorless field-oriented (FO) control of induction motor drives.

The presented models are derived from the dynamical machine model. These models are represented by linear regression equations from which machine parameter vectors may be obtained using the RLS estimation algorithm. Moreover, a robust speed 
estimator based on the MRAS is proposed. This estimator contains the estimated parameters to achieve high-precise control in a wide range of motor speed. The estimated motor speed is used in the linear regression equations and is used as feedback signal in a speed sensorless FO control system. The different estimation algorithms can provide good estimation accuracy of parameters at any load conditions and be easily introduced with the speed sensorless FO control system. Simulation results are presented which demonstrate the effectiveness of the proposed scheme. The results clarify satisfactory operation of the proposed scheme and reasonable accuracy of estimated machine parameters.

\section{DYNAMIC MODEL OF AN INDUCTION MOTOR}

The mathematical model of an induction motor in a stationary $\alpha-\beta$ reference frame can be described by a state-space equation as [1]:

$$
p x(t)=A x(t)+B u(t)
$$

where $\quad x=\left[\begin{array}{ll}i_{s} & \psi_{r}\end{array}\right]^{T}$ and $u=V_{s}$

The state space vectors are complex quantities defined as:

$$
i_{s}=i_{\alpha s}+j i_{\beta s}, \quad \psi_{r}=\psi_{\alpha r}+j \psi_{\beta r}
$$

The input vector is a complex quantity given by $V_{s}=V_{\alpha s}+j V_{\beta s}$

The dynamic matrix $A$ and the input matrix $B$ of equation (1) are given by

$$
A=\left[\begin{array}{rr}
-\frac{\left(R_{s}+R_{r}\left(L_{m}^{2} / L_{r}^{2}\right)\right)}{\sigma L_{s}} & \frac{L_{m}}{T_{r}} \\
\frac{L_{m}}{T_{r}} & -\frac{1}{T_{r}}+j \omega_{r}
\end{array}\right]^{T} \quad \text { and } \quad B=\left[\begin{array}{cc}
\frac{1}{\sigma L_{s}} & 0
\end{array}\right]^{T}
$$

The use of system estimation techniques in this work is based on a discretetime representation of the induction motor behavior. To derive the discrete-time version of equation (1) it is assumed that the stator voltage vector is supplied to the motor through a zero order hold device such as the voltage source inverter. Furthermore, the motor speed $\omega_{r}$ is assumed to remain constant during the sampling interval $\Delta t$, i.e. the mechanical modes are slower than the electrical ones. Under these assumptions, the discrete-time representation of equation (1) is expressed as

$$
\delta x(t)=F x(t)+G u(t)
$$

where $\delta$ is the delta operator [19], $\delta x(t)=(x(t+\Delta t)-x(t)) / \Delta t$ or $\delta=q-1 / \Delta t$ where $\Delta t$ is the sampling period and $q$ is the shift operator.

The matrices $F$ and $G$ of the discrete-time model are determined by

$$
F=\frac{e^{A \Delta t}-I}{\Delta t} \quad \text { and } \quad G=A^{-1}\left(\frac{e^{A \Delta t}-I}{\Delta t}\right) B
$$


From equation (3), it is clear that $\lim _{\Delta t \rightarrow 0} F=A$ and $\lim _{\Delta t \rightarrow 0} G=B$ it high sampling rates.

The discrete-time model can be replaced by its continuous-time counter part using the power series expression of $e^{A \Delta t}$. As a result $F$ and $G$ can also expressed by

$$
F=\sum_{n=0}^{\infty} \frac{A^{n+1} \Delta t^{n}}{(n+1) !} \quad \text { and } \quad G=\sum_{n=0}^{\infty} \frac{(A \Delta t)^{n}}{(n+1) !} B
$$

Equation (2) may be expanded, by using the complex quantities defined previously [19] and may be rewritten as:

$$
\left[\begin{array}{l}
\delta i_{s} \\
\delta \psi_{r}
\end{array}\right]=\left[\begin{array}{ll}
f_{11} & f_{12} \\
f_{21} & f_{22}
\end{array}\right]\left[\begin{array}{l}
i_{s} \\
\psi_{r}
\end{array}\right]+\left[\begin{array}{l}
g_{11} \\
g_{21}
\end{array}\right] V_{s}
$$

where $\quad f_{m n}=f_{m n x}+j f_{m n y}, \quad g_{m 1}=g_{m 1 x}+j g_{m 1 y}, m=1,2, n=1,2$.

After some algebraic manipulations, it is possible to eliminate the rotor flux terms from equation (5), resulting in

$$
\delta^{2} i_{s}=f_{1} \delta i_{s}+f_{0} i_{s}+g_{1} \delta V_{s}+g_{0} V_{s}
$$

where $f_{1}=f_{11}+f_{22}=f_{1 x}+j f_{1 y}$

$$
\begin{aligned}
& f_{0}=f_{12} f_{21}-f_{22} f_{11}=f_{0 x}+j f_{0 y} \\
& g_{1}=g_{11}=g_{1 x}+j g_{1 y}
\end{aligned}
$$

and $\quad g_{0}=f_{12} g_{21}-f_{22} g_{11}=g_{0 x}+j g_{0 y}$

Equation (6) represents the basic equation used to formulate the parameter estimation problem. It is possible to show that some parameters of the state-space model (equation (2) or equation (5)) can be recovered once the parameters of equation (6) have been determined. By assuming that $f_{1}, f_{0}, g_{1}$ and $g_{0}$ are determined, it is possible to calculate

$$
g_{11}=g_{1}
$$

If the sampling rate is sufficiently high, the discrete-time model can be approximated by its continuous-time counter part, i.e., $F=A$ and $G=B$ and consequently $g_{21}=B_{21}=0$ which yields

$$
\begin{aligned}
& f_{22}=-g_{0} / g_{1} \\
& f_{11}=f_{1}+g_{0} / g_{1} \\
& f_{12} f_{21}=f_{0}-\frac{g_{0}}{g_{1}}\left(f_{1}+g_{0} / g_{1}\right)
\end{aligned}
$$


and then, the model given by equation (6) becomes

$$
\begin{aligned}
\delta^{2} i_{s}=-\left(\frac{R_{s}+L_{s} / T_{r}}{\sigma L_{s}}\right. & \left.+j \omega_{r}\right) \delta i_{s}-\frac{R_{s}}{\sigma L_{s}}\left(\frac{1}{T_{r}}+j \omega_{r}\right) i_{s} \\
& +\frac{1}{\sigma L_{s}} \delta V_{s}+\frac{1}{\sigma L_{s}}\left(\frac{1}{T_{r}}+j \omega_{r}\right) V_{s}
\end{aligned}
$$

In terms of real and imaginary components of $V_{s}$ and $i_{s}$ vectors, the continuous-time model given by equation (15) can be rewritten as:

$$
\begin{aligned}
& {\left[\begin{array}{c}
\delta^{2} i_{\alpha s} \\
\delta^{2} i_{\beta s}
\end{array}\right]=\left[\begin{array}{cc}
-\left(\frac{R_{s}+L_{s} / T_{r}}{\sigma L_{s}}\right) & -\omega_{r} \\
\omega_{r} & -\left(\frac{R_{s}+L_{s} / T_{r}}{\sigma L_{s}}\right)
\end{array}\right]\left[\begin{array}{l}
\delta i_{\alpha s} \\
\delta i_{\beta s}
\end{array}\right]+\left[\begin{array}{cc}
-\frac{R_{s}}{\sigma L_{s} T_{r}} & -\frac{\omega_{r} R_{s}}{\sigma L_{s}} \\
\frac{\omega_{r} R_{s}}{\sigma L_{s}} & -\frac{R_{s}}{\sigma L_{s} T_{r}}
\end{array}\right]\left[\begin{array}{l}
i_{\alpha s} \\
i_{\beta s}
\end{array}\right]} \\
& +\left[\begin{array}{cc}
\frac{1}{\sigma L_{s}} & 0 \\
0 & \frac{1}{\sigma L_{s}}
\end{array}\right]\left[\begin{array}{l}
\delta V_{\alpha s} \\
\delta V_{\beta s}
\end{array}\right]+\left[\begin{array}{cc}
\frac{R_{s}}{\sigma L_{s} T_{r}} & \frac{\omega_{r}}{\sigma L_{s}} \\
-\frac{\omega_{r}}{\sigma L_{s}} & \frac{R_{s}}{\sigma L_{s} T_{r}}
\end{array}\right]\left[\begin{array}{c}
V_{\alpha s} \\
V_{\beta s}
\end{array}\right]
\end{aligned}
$$

This also represents that $\delta x(t)=p x(t)$, where $p=d / d t$, since the delta operator can be interpreted as the forward-difference approximation of the differential operator.

\section{REAL TIME PARAMETER ESTIMATION BASED ON RLS ALGORITHM}

To estimate the motor parameters using the RLS algorithm, it is necessary to rewrite the model of equation (16) in the form of a regression equation such as:

$$
y(t)=\Gamma(t) \beta
$$

where $y(t), \Gamma(t)$ and $\beta$ are the prediction vector, the regression matrix and the unknown parameters vector respectively. Equation (16) may be rewritten as linear regression model simply by defining

$$
\begin{aligned}
y(t) & =\left[\begin{array}{l}
\delta^{2} i_{\alpha s} \\
\delta^{2} i_{\beta s}
\end{array}\right] \\
\Gamma(t) & =\left[\begin{array}{rrrrrrr}
-\delta i_{\alpha s} & -\delta i_{\beta s} & -i_{\alpha s} & -i_{\beta s} & -\delta V_{\alpha s} & V_{\alpha s} & V_{\beta s} \\
-\delta i_{\beta s} & \delta i_{\alpha s} & -i_{\beta s} & i_{\alpha s} & \delta V_{\beta s} & V_{\beta s} & -V_{\alpha s}
\end{array}\right]
\end{aligned}
$$

and $\beta=\left[\begin{array}{lllllll}\frac{R_{s} L_{r}+R_{r} L_{s}}{\sigma L_{s} L_{r}} & \omega_{r} & \frac{R_{s}}{\sigma L_{s} T_{r}} & \frac{R_{s} \omega_{r}}{\sigma L_{s}} & \frac{1}{\sigma L_{s}} & \frac{1}{\sigma L_{s} T_{r}} & \frac{\omega_{r}}{\sigma L_{s}}\end{array}\right]$ 
The RLS algorithm for a regression model computes the unknown estimated parameters vectors $\hat{\beta}(N)$ in such a way that the weighted quadratic cost function is minimized for $N$ successive instants samples:

$$
C=\sum_{n=1}^{N}|y(n)-\Gamma(n) \hat{\beta}(n)|^{2}
$$

The basic equations of the RLS estimation algorithm used to calculate the unknown parameters $\beta$ can be found in [19]. In this algorithm, the time variation of the parameters is taken into account by the forgetting factor $\alpha(n)$. The forgetting factor is used to track the time variation of the unknown parameters.

\subsection{Estimation Model of Stator Resistance}

The stator resistance estimation together with the other parameters may cause in general an inaccurate estimation. Then, it is wise to develop a model to estimate the stator resistance independently of other parameters. If the machine is supplied with dc quantities, i.e. the stator frequency $\omega_{s}=0$, equation (16) can be written as follows:

$$
V_{s}=R_{s} i_{s}
$$

Then, the regression model may be represented by

$$
\begin{array}{r}
y(t)=\left[\begin{array}{ll}
V_{\alpha s} & V_{\beta s}
\end{array}\right]^{T} \\
\Gamma(t)=\left[\begin{array}{ll}
i_{\alpha s} & i_{\beta s}
\end{array}\right]^{T}
\end{array}
$$

and

$$
\beta=\left[R_{s}\right]
$$

The stator resistance estimator is accomplished online by adding a dc bias to the reference signals. This estimated value is considered when the stator windings are supplied with PWM waveforms and the machine is running under normal operating conditions.

\subsection{Estimation Model of Stator Leakage Inductance}

From equation (16) it is possible to derive the following regression model if the stator resistance has already been estimated.

$$
\begin{aligned}
& y(t)=\left[\begin{array}{l}
-\delta u_{\alpha s}-\omega_{r} u_{\beta s} \\
-\delta u_{\beta s}+\omega_{r} u_{\beta s}
\end{array}\right] \\
& \Gamma(t)=\left[\begin{array}{lll}
-\delta^{2} i_{\alpha s}-\omega_{r} \delta i_{\beta s} & u_{\alpha s} & -\delta i_{\alpha s} \\
-\delta^{2} i_{\beta s}+\omega_{r} \delta i_{\alpha s} & u_{\beta s} & -\delta i_{\beta s}
\end{array}\right] \\
& \beta=\left[\begin{array}{lll}
\sigma L_{s} & \frac{1}{T_{r}} & \frac{L_{s}}{T_{r}}
\end{array}\right]^{T}
\end{aligned}
$$

where $u_{\alpha s}=V_{\alpha s}-R_{s} i_{\alpha s} \quad$ and $\quad u_{\beta s}=V_{\beta s}-R_{s} i_{\beta s}$

When the machine is supplied with sinusoidal PMW waveform, only the leakage inductance can be estimated with good accuracy. Due to high frequency 
components present in the voltage and current waveforms, the ratio $\frac{\partial y(t)}{\partial\left(\sigma L_{s}\right)}$ becomes dominant over the other terms of the regression model.

By using equations (25)-(27), one may obtain $\sigma L_{s}$ as long as $\omega_{r}$ is available from speed estimator. A simpler model to determine $\sigma L_{s}$ independently of $\omega_{r}$ is possible. If the excitation frequency is sufficiently high such that $\omega_{s} \omega_{r}$, the model given by (16) can be approximated by

$$
V_{s h}=\sigma L_{s} \delta i_{s h}
$$

where the subscript $h$ in the above equation stands for the high frequency components of voltages and currents.

Then, from equation (28) the following regression model can be obtained

$$
\begin{aligned}
& y(t)=\left[\begin{array}{ll}
V_{\text {shd }} & V_{\text {shq }}
\end{array}\right]^{T} \\
& \Gamma(t)=\left\lfloor\begin{array}{ll}
\delta i_{\text {shd }} & \delta i_{\text {shq }}
\end{array}\right] \\
& \beta=\left[\sigma L_{s}\right]
\end{aligned}
$$

\subsection{Estimation Model of Rotor Time Constant and Stator Self Inductance}

To derive the equations for this model, it is assumed that the stator resistance, leakage inductance and motor speed have been previously estimated.

In this case, one may derive from (16) the following regression model

$$
\begin{aligned}
& y(t)=\left[\begin{array}{l}
\delta^{2} i_{\alpha s}-\frac{1}{\sigma L_{s}} \delta u_{\alpha s}-\omega_{r} \delta i_{\beta s}-\frac{\omega_{r}}{\sigma L_{s}} u_{\beta s} \\
\delta^{2} i_{\beta s}-\frac{1}{\sigma L_{s}} \delta u_{\beta s}+\omega_{r} \delta i_{\alpha s}+\frac{\omega_{r}}{\sigma L_{s}} u_{\sigma s}
\end{array}\right] \\
& \Gamma(t)=\left[\begin{array}{ll}
-\frac{1}{\sigma L_{s}} \delta i_{\alpha s} & \frac{1}{\sigma L_{s}} u_{\alpha s} \\
-\frac{1}{\sigma L_{s}} \delta i_{\beta s} & \frac{1}{\sigma L_{s}} u_{\beta s}
\end{array}\right] \\
& \text { and } \quad \beta=\left[\begin{array}{ll}
\frac{L_{s}}{T_{r}} & \frac{1}{T_{r}}
\end{array}\right]^{T}
\end{aligned}
$$

The unknown parameters $\beta$ of the discrete-time model can be determined using equations (32)-(34). The estimated rotor time constant $\left(T_{r}\right)$ is used in the slip calculator of the IFO control to achieve proper field orientation. 


\section{ROBUST SPEED ESTIMATION BASED ON MRAS TECHNIQUES FOR AN IFO CONTROL}

Field-oriented control allows high-performance control of speed and torque of achieved induction motors. A speed sensor is usually requisite for FO control. In practical applications, the use of speed sensor not only spoils the ruggedness and simplicity of induction motor scheme, but also, it increases the cost and complicity of the control system. A speed estimation scheme based on a robust MRAS has been proposed and evaluated for speed sensorless IFO control of induction motor drives. This scheme is based on the measurement of stator voltages and currents. The motor voltages and currents are calculated in a stationary $\alpha-\beta$ reference frame, it is convenient to express the stator and rotor model of the induction motor in the stationary reference frame [11]:

Reference model (stator equation).

$$
p\left[\begin{array}{l}
\psi_{\alpha r} \\
\psi_{\beta r}
\end{array}\right]=\frac{L_{r}}{L_{m}}\left(\left[\begin{array}{c}
V_{\alpha s} \\
V_{\beta s}
\end{array}\right]-\left[\begin{array}{cc}
\left(R_{s}+\sigma L_{s} p\right) & 0 \\
0 & \left(R_{s}+\sigma L_{s} p\right)
\end{array}\right]\left[\begin{array}{c}
i_{\alpha s} \\
i_{\beta s}
\end{array}\right]\right)
$$

Adjustable model (rotor equation)

$$
p\left[\begin{array}{l}
\psi_{\alpha r} \\
\psi_{\beta r}
\end{array}\right]=\left[\begin{array}{lr}
\left(-1 / T_{r}\right) & -\omega_{r} \\
\omega_{r} & \left(-1 / T_{r}\right)
\end{array}\right]\left[\begin{array}{l}
\psi_{\alpha r} \\
\psi_{\beta r}
\end{array}\right]+\frac{L_{m}}{T_{r}}\left[\begin{array}{c}
i_{\alpha s} \\
i_{\beta s}
\end{array}\right]
$$

The stator equation expressed by equation (35) does not involve motor speed $\omega_{r}$, while the rotor equation expressed by equation (36) does. The MRAS technique depends on the comparison between the rotor flux outputs of these two models and adjusting the value $\omega_{r}$ in the rotor equation for minimizing the resulting flux error.

The adjustment value of motor speed $\hat{\omega}_{r}$ is generated from the error between the reference and adjustable model observation by using a suitable adaptation mechanism as [18]:

$$
\hat{\omega}_{r}=\left(K_{P}+\frac{K_{I}}{s}\right) \varepsilon
$$

where $\varepsilon=\left(\hat{\psi}_{\alpha r} \psi_{\beta r}-\hat{\psi}_{\beta r} \psi_{\alpha r}\right)$

Figure 3 shows the block diagram of the speed estimation MRAS based on this adaptation mechanism. Notice that the factors $L_{r} / L_{m}$ in equation (35) and $L_{m} / T_{r}$ in (36) have conveniently been incorporated into the adaptation mechanism gain constants $K_{p}$ and $K_{I}$. The outputs of the two models thus only represent the rotor flux components and all variables are expressed in the stationary reference frame so that the input voltages $V_{\alpha s}, V_{\beta s}$ and currents $i_{\alpha s}, i_{\beta s}$ are obtained from measurements. As shown in the system of figure 3 , the only remaining parameters are $\left(R_{s}, \sigma L_{s}\right.$ and $T_{r}$ ). The output of the reference model of the speed estimator is sensitive to the stator resistance which changes with motor temperature. Also, the stator leakage inductance 
is included in the reference model and the estimated speed is critically affected over the whole speed range due to variation of the leakage inductance with change of the load torque.

On the other hand, the output of the adjustable model of the estimator is influenced by the rotor time constant which varies significantly with the rotor temperature, frequency (skin effect) and magnetic saturation.

Thus, these parameters $\left(R_{s}, \sigma L_{s}\right.$ and $\left.T_{r}\right)$ have strong influence upon the motor speed estimation. In order to estimate the motor speed accurately the estimated stator resistance and leakage inductance based on equations (22)-(24) and equations (25)-(27) respectively are employed to correct the reference model output. Also, the estimated rotor time constant based on equations (32)-(36) is used to correct the adjustable model output. Therefore, the MRAS estimator is robust against motor parameter variations.

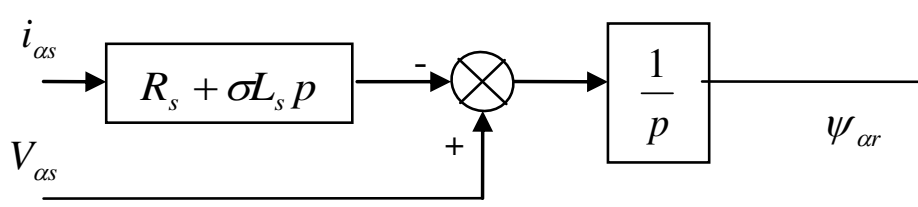

$V_{\beta s}$
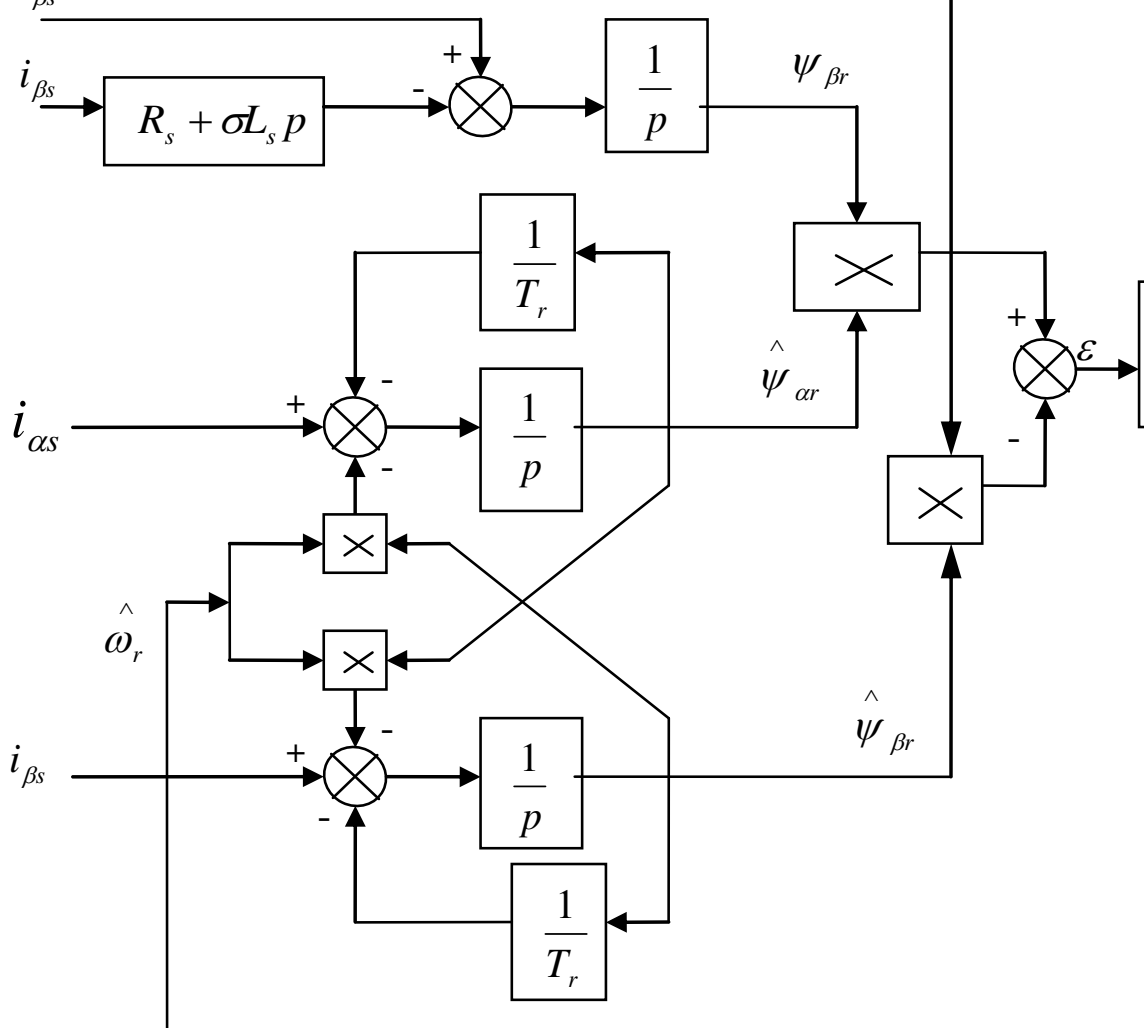

$K_{P}+\frac{K_{I}}{p}$

Figure 3: Block diagram of MRAS speed estimation system 


\section{PROPOSED SENSORLESS IFO CONTROL SCHEME}

To achieve ideal decoupling between the direct and quadrature axes, the rotor flux linkage would be aligned along the d-axis, i.e.

$$
\psi_{q r}=0 \quad \text { and } \quad \psi_{d r}=\psi_{r}
$$

If the rotor flux is set constant according to the operation requirements, the torque equation becomes

$$
\begin{aligned}
& T_{e}=K_{T} i_{q s} \quad \text { where } \quad K_{T}=\frac{3}{2} P \frac{L_{m}}{L_{r}} \psi_{r} \quad \text { and the slip speed is defined as : } \\
& \omega_{s l}=\frac{1}{T_{r}} \frac{i_{q s}}{i_{d s}}
\end{aligned}
$$

In the IFO control scheme, the stator current components $i_{d s}^{*}$ and $i_{q s}^{*}$ are respectively, the magnetizing and torque current commands.

Figure 4 shows a block diagram of the proposed speed sensorless IFO control of an induction motor drive system based on MRAS estimator. The control system is composed of classical PI (proportional-integral) speed controller, two current controllers, vector rotator, a digital pulse width modulation (PWM) scheme for a transistor bridge voltage source inverter (VSI), a motor speed estimator based on MRAS and stator resistance, leakage inductance and rotor time constant estimators using RLS algorithm. In the speed controller, the speed is corrected by the error between the command and estimated motor speed. The speed controller is to generate the command q-component of stator current $i_{q s}^{*}$. The two current controllers of Fig. 4 are included for controlling the torque-producing current-component (q-axis current controller) and the magnetizing current component (d-axis current controller). Since the quantities to be adjusted by these current controllers are dc quantities, a classical PI control technique can be successfully employed. The output of these controllers are the $\mathrm{d}$-axis and q-axis components of stator voltage commands $\left(V^{*}{ }_{d s}\right.$ and $\left.V^{*}{ }_{q s}\right)$. The vector rotator in Fig. 4 is used for transforming $V^{*}{ }_{d s}$ and $V^{*}{ }_{q s}$ to the three-phase stator voltage commands $\left(V^{*}{ }_{a s} V^{*}{ }_{b s}\right.$ and $\left.V^{*}{ }_{c s}\right)$ by using the field angle $\theta_{s}$.

The control inputs to the PWM block are the stator voltage commands and predefined triangular carrier waves. In the PWM scheme, the inverter output voltage is defined by the intersections of the stator voltage commands and carrier waves, which are synchronized such that the carrier frequency is an integer multiple of the frequency of stator voltage commands. This manner of synchronization eliminates subharmonic generation. The output of the inverter is the input to the induction motor. The speed estimator calculates the speed $\hat{\omega}_{r}$ directly from the stator phase voltages and currents after being transformed to the $\alpha$ - and $\beta$ - components. This estimated speed is fed back to the speed controller. Also, the estimated speed is added to the slip speed and the sum is integrated for obtaining the field angle $\theta_{s}$.

The estimated rotor time constant is used in the slip speed calculator to update the estimated value of slip speed. The estimated stator resistance, leakage inductance and the estimated rotor time constant are used to correct the calculation of reference model and adjustable model outputs respectively, of the MRAS. 


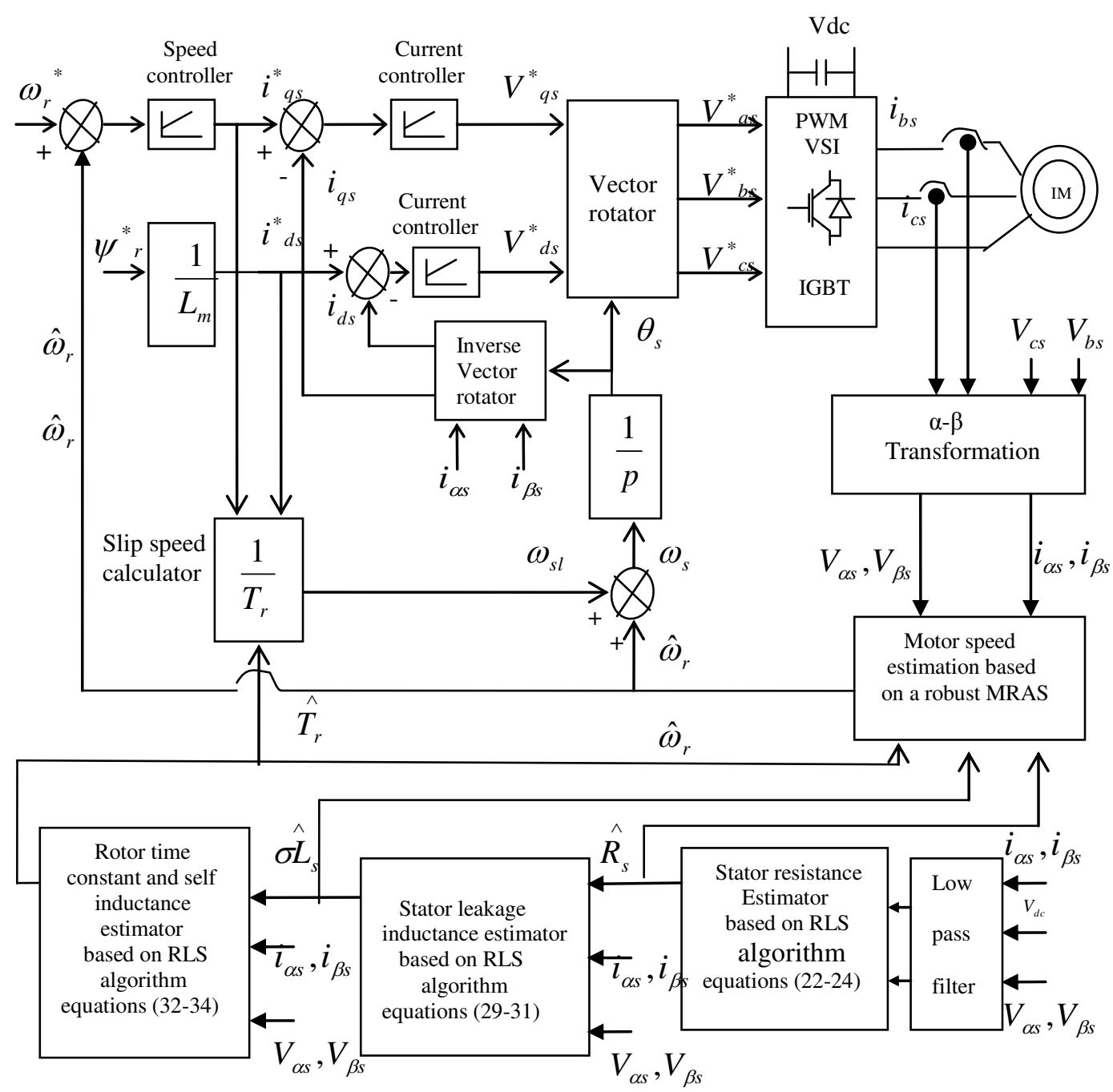

Figure 4: Overall block diagram of the proposed sensorless IFO control drive system

\section{SIMULATION RESULTS AND DISCUSSION}

In order to verify the validity and the performance of the proposed scheme of Fig. 4, computer simulations have been carried out using Matlab software. The test motor was a 9.8 H.P, $220 \mathrm{~V}, 50 \mathrm{~Hz}$, delta connected, slip-ring induction motor. The rated current per phase was $15.1 \mathrm{~A}$ at $1450 \mathrm{rpm}$. Coupled to the motor was a DC generator of about the same rating. The equivalent circuit parameters for the motor were determined by the no-load and locked rotor tests (standard tests), in the usual manner.

The parameter estimation procedure is carried out using the presented regression equations and the RLS algorithm with forgetting factor. The sampling time is set to $\Delta t=40 \mu \mathrm{sec}$ and the forgetting factor $=0.99$. The machine is to be supplied by a three phase PWM voltage source inverter which is controlled by the IFO control 
method. The parameter estimation algorithm runs with the data generated by simulation program. Table 1 illustrates the estimated mean values of electrical motor parameters obtained using the RLS algorithm and those obtained experimentally (standard tests). The third row shows the percentage error results. It can be noted that it is possible to estimate all electrical parameters with good precision (estimation errors between 2-4\%). These errors are small and tolerated to get good parameters estimation.

\section{Table 1 Estimated and standard induction motor parameters}

\begin{tabular}{|c|c|c|c|c|}
\hline Electrical parameters & $R_{s}(\mathrm{Ohm})$ & $\sigma L_{s}$ (Henry) & $L_{s}$ (Henry) & $T_{r}$ (Sec.) \\
\hline Using RLS algorithm & 0.5260 & 0.0072 & 0.1169 & 0.2287 \\
\hline Experimentally & 0.5120 & 0.0069 & 0.1215 & 0.2341 \\
\hline \% lerrorl & $2.7 \%$ & $4 \%$ & $3.8 \%$ & $2.3 \%$ \\
\hline
\end{tabular}

Figure 5 shows the simulation results for stator resistance estimation with $\mathrm{dc}+$ sinusoidal waveform using the estimated model of equations (21)-(23). The estimation of the stator resistance in this case is obtained using a first-order low pass filter with suitable cutoff frequency to reduce the estimation time. The average value of the estimated stator resistance $\left(\hat{R_{s}}=0.526 \mathrm{ohm}\right)$ is in reasonable agreement with the measured one.

Figure 6 shows the simulation results for stator leakage inductance estimation with model given by equations (24)-(26) and the previously estimated stator resistance is employed in this model. From this figure, it can be seen that the estimates converge quickly to the measured one and only the initial high transient peak ( about 0.05 henry) due to the startup of the RLS algorithm is observed.

Figures 7 and 8 show the simulation results for the rotor time constant and the stator self inductance estimations as obtained from equations (27)-(29). The previously estimated values of stator leakage inductance, stator resistance and motor speed are used with this model. It can be seen from these figures that the estimated values of rotor time constant and stator self inductance provide good performance i.e. fast convergence time and limited estimation errors.

From these figures 5-8, it can be seen that, the different estimated parameters follow the measured one very closely which indicates that the presented estimation procedure worked successful for motor parameter estimation. These results are confirmed by Table1 Figure 9 shows the simulation results of motor speed estimation for conventional MRAS estimator using the standard parameters $\left(R_{s}, \sigma L_{s}\right.$ and $\left.T_{r}\right)$. This figure exhibits undesirable oscillations on the motor speed due to the influence of misestimated of the motor parameters. The estimated motor speed response of conventional MRAS estimator is unacceptable for speed sensorlees drive applications. Figure 10 shows the motor speed estimation for the proposed MRAS estimator using the estimated parameters $\left(\hat{R}_{s}, \hat{\sigma}_{s}\right.$ and $\left.\hat{T}_{r}\right)$ in the estimator to compensate the effects of their variations on the accuracy of the speed estimation.. This figure indicates that 
the estimated motor speed is well matched and agrees satisfactorily with its actual one. Also, the motor speed is estimated with mean error less than $0.5 \%$. It is clear that a speed estimator with such an error can be used to replace speed sensor.

The presented estimation methodology is evaluated by comparing the waveform of the stator current obtained by simulation using the estimated parameters with the waveform obtained from using the measured ones.

Figure 11 shows the $\alpha$-axis stator current component error $\left(e_{\alpha s}=\hat{i_{\alpha s}}-i_{\alpha s}\right)$ between the simulated stator current component using estimated parameters and the corresponding current obtained using the measured ones. The $\beta$-axis stator current component error $\left(e_{\beta s}=\hat{i_{\beta s}}-i_{\beta s}\right)$ is illustrated in the same figure. As noted from this figure, the errors of the stator currents components have been increased to about \pm 1.7 A due to the small deviations of the measured parameters from their estimated ones. Figure 12 compares the simulated stator current vector obtained using the estimated parameters $\hat{i}_{s}$ and the simulated current vector obtained using the measured ones. From this figure, it is obvious that the simulated stator current vector $i_{s}$ with the standard parameters shift from the centre of the circle due to the small difference between the estimated parameters and standard ones.

The transient behavior of the proposed sensorless IFO control system is evaluated for an acceleration to $75 \mathrm{rad} . / \mathrm{sec}$., followed by the application of the motor rated torque $(50 \mathrm{~N} . \mathrm{m})$ and the removal of this torque as shown in figure 13.

Figure 13a shows that the motor speed can be effectively estimated and have the same track as the actual one with the proposed sensorless scheme. Figure 13b indicates that a fast and precise transient response of the motor torque is achieved. Also, the stator phase current matches the value of the application and removal of the motor rated torque as shown in Fig. 13c.

The worst condition under which the sensorless drive system can operate is with disconnected load. In this case the inertia is low and the fastest speed transients appear. Some speed transients with disconnected load are shown in figures 14 and 15 . In figure 14 the actual and estimated speed transient, motor torque and stator phase current are shown during the forward-reverse operation (up to $10 \%$ of its rated speed $=15$ rad./sec.) under no load condition. This figure shows that the proposed sensorless drive system exhibits excellent dynamic performance during speed transients. The incorporation of the estimated parameters $\left(\hat{R}_{s}, \sigma \hat{L}_{s}\right.$ and $\left.\hat{T}_{r}\right)$ in the MRAS estimator ensures correct speed estimation during transient operation. The actual and estimated motor speed has the same track as shown in figure $14 \mathrm{a}$. The motor torque gives a desired performance as shown in figure 14b.The stator phase current during the speed transient is dedicated as shown in figure 14c. Moreover, the drive system operates stably at zero speed. Figure 15 shows the actual and estimated speed transient, motor torque and stator phase current during acceleration to $120 \%$ of its rated speed (180 rad./sec.). The estimated speed agreed satisfactorily with the actual one as shown in figure 15a. Also, it has small deviation from its actual one before reaching steady-state with a subsequent fast tracking towards the command value. The motor torque response exhibits good dynamic performance as shown in figure 15b. Figure 15c 
shows the stator phase current during speed acceleration. From the simulation results, it is seen that there is only a small estimation error during speed transients. The proposed sensorless drive system is capable of operation at high speed as illustrated in figure 15.

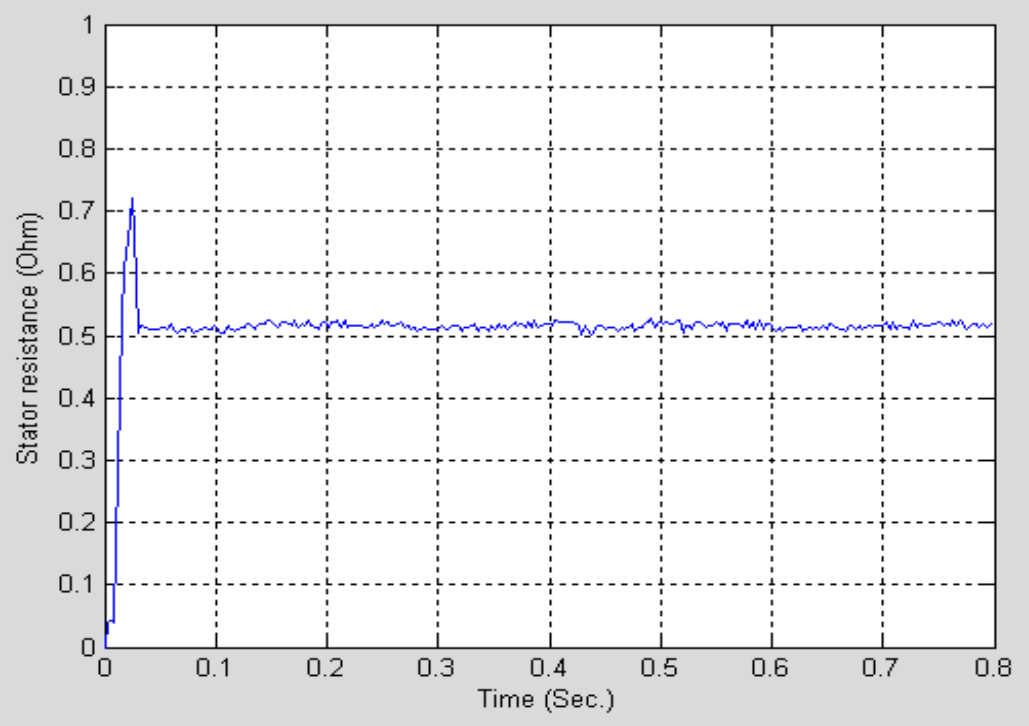

Figure 5: Simulation results of stator resistance estimation

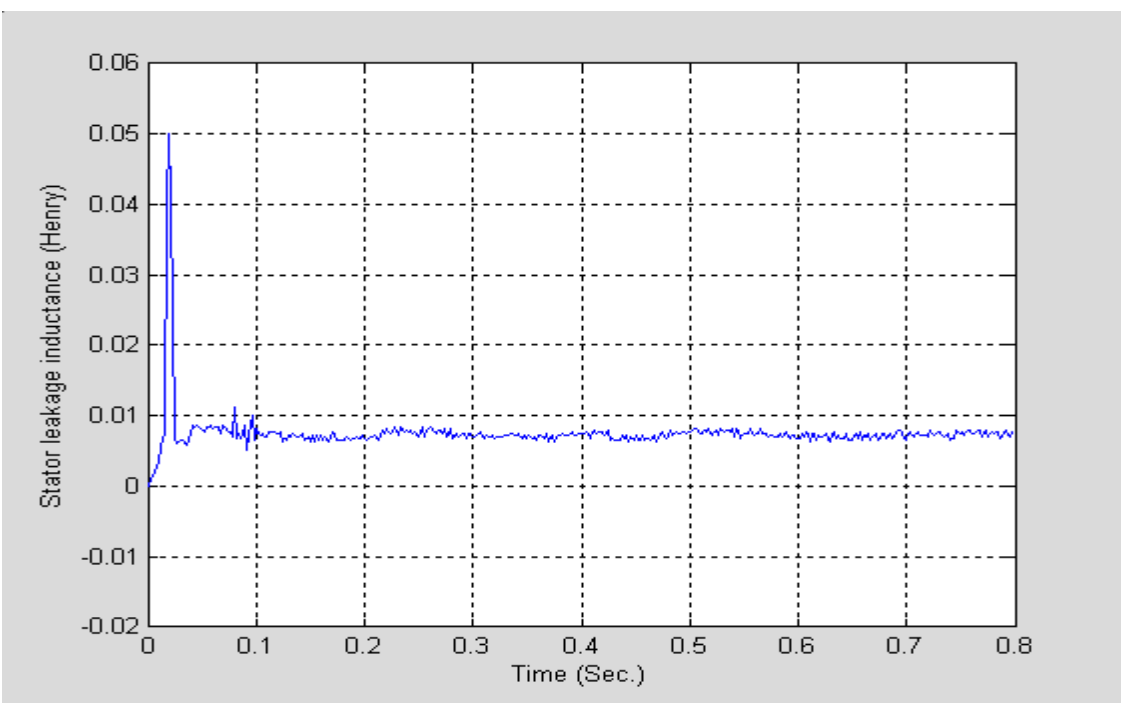

Figure 6: Simulation results of stator leakage inductance estimation 


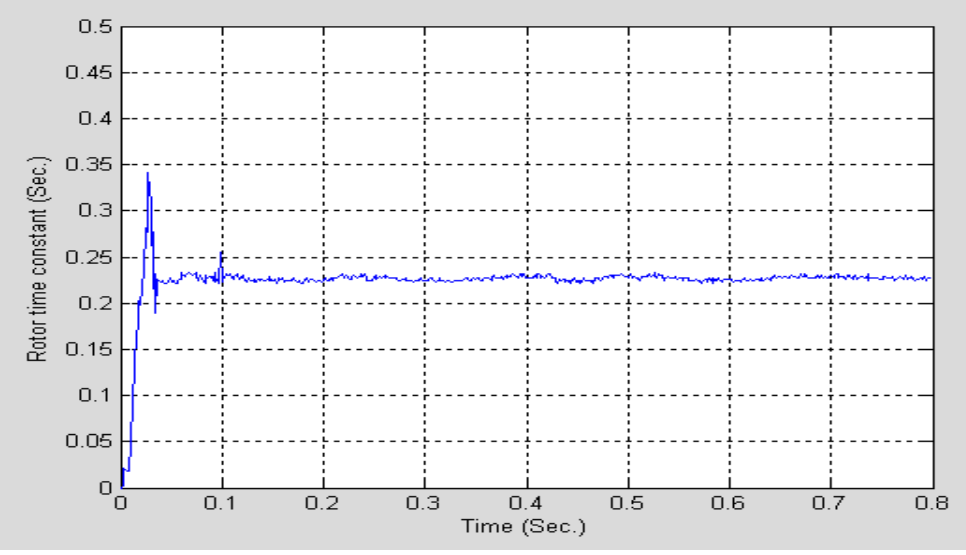

Figure 7: Simulation results of rotor time constant estimation

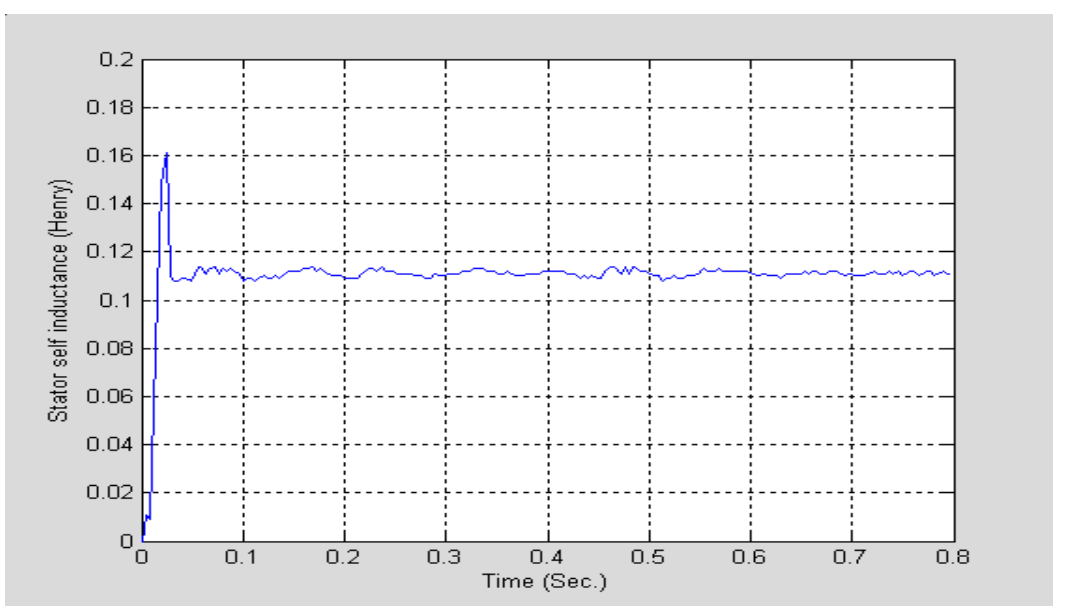

Figure 8: Simulation results of stator self inductance estimation

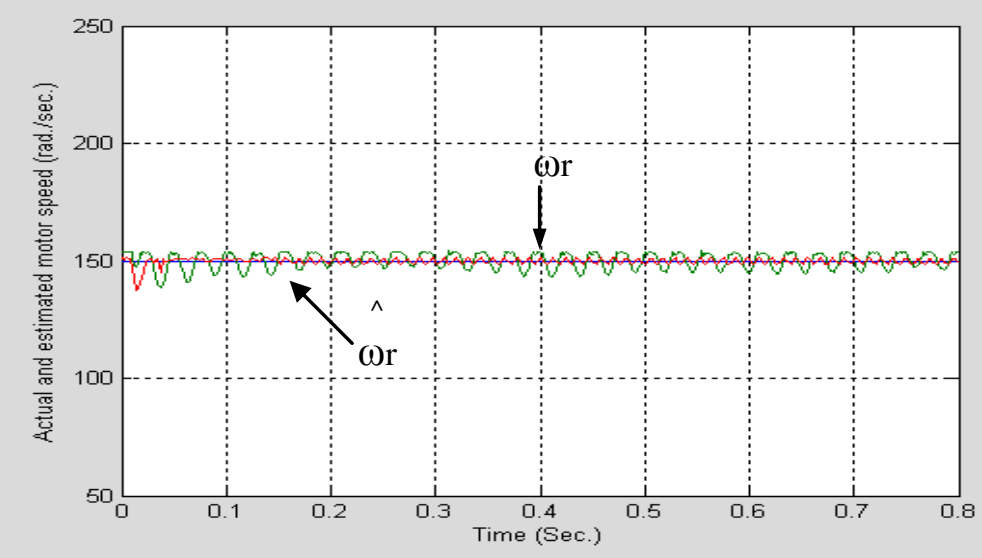

Figure 9: Actual and estimated motor speed using conventional MRAS 


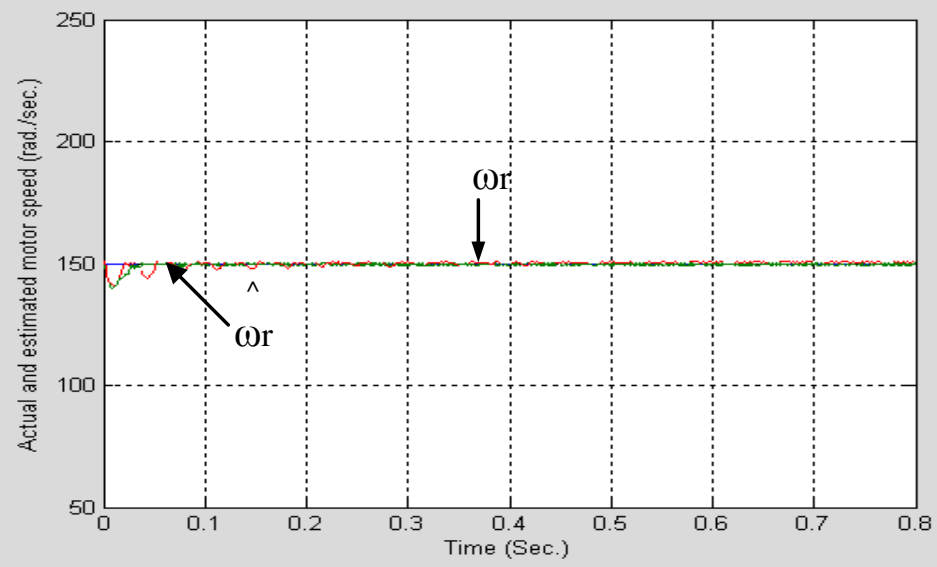

Figure 10: Actual and estimated motor speed using proposed MRAS

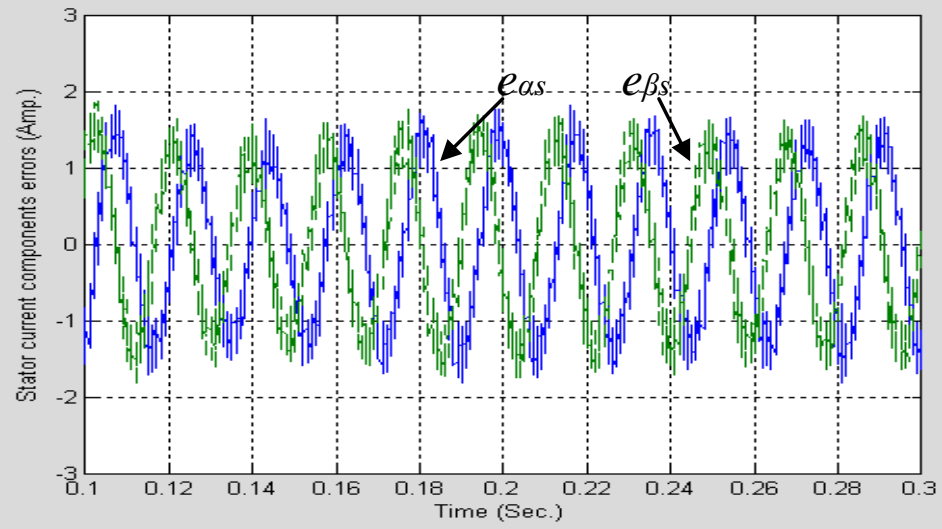

Figure 11: $\alpha$-axis and $\beta$-axis stator currents errors

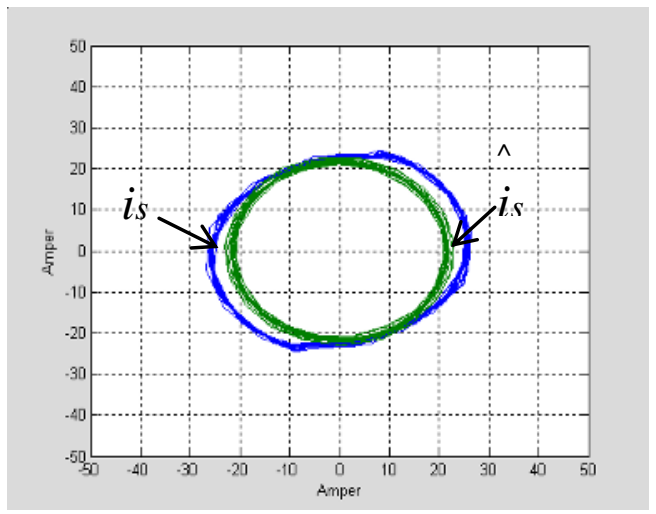

Figure 12: Comparison between the simulated $\hat{i_{s}}$ using the estimated parameters and the simulated $i_{s}$ using the standard ones 


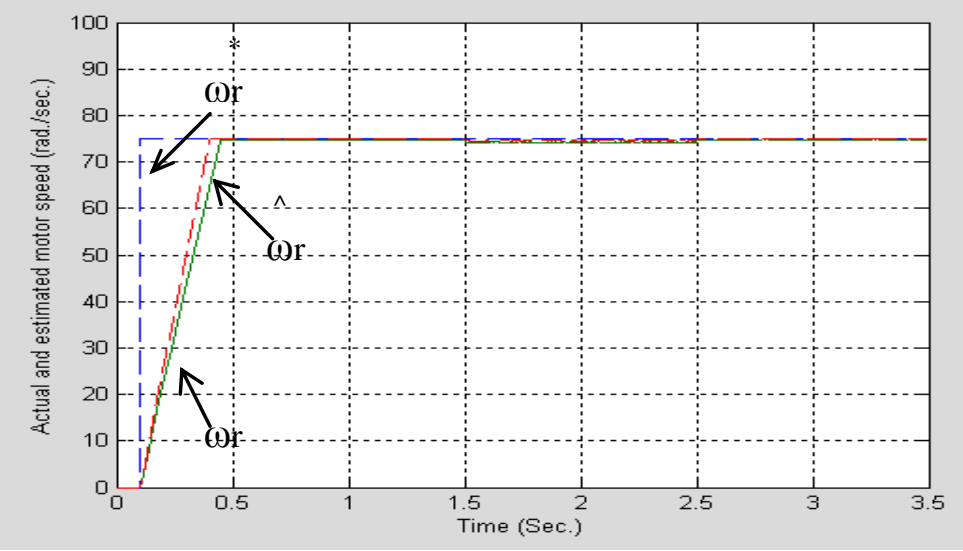

(a) Actual motor speed (-) and estimated motor speed (---)

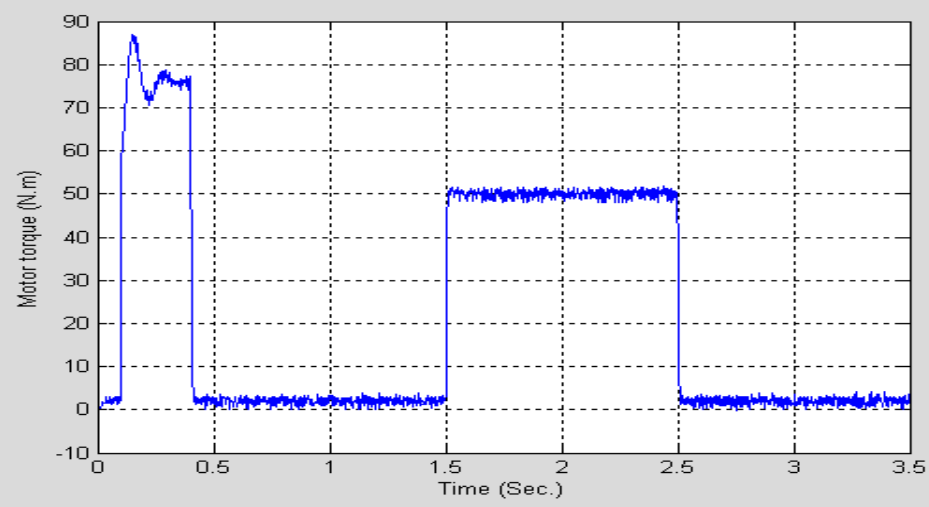

(b) Motor torque

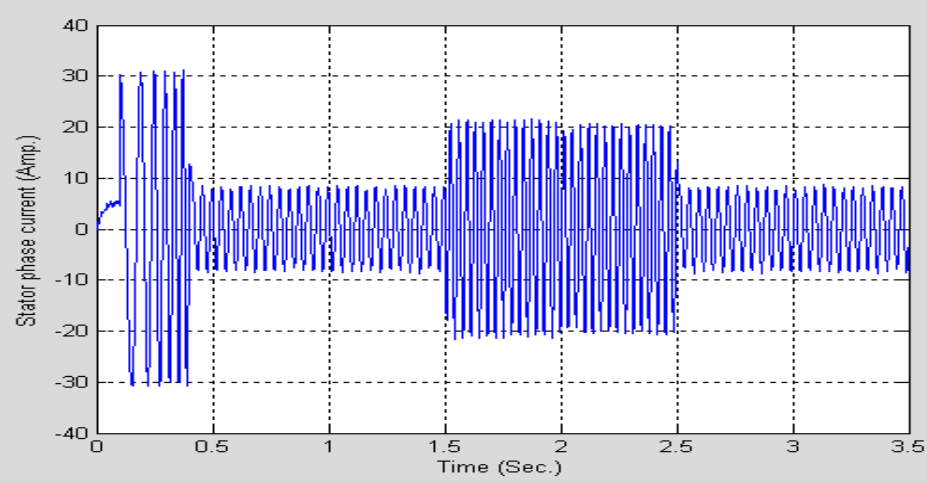

(c) Stator phase current

Figure 13: Simulation results of speed transient with load step changes of rated value using the proposed sensorless drive system 


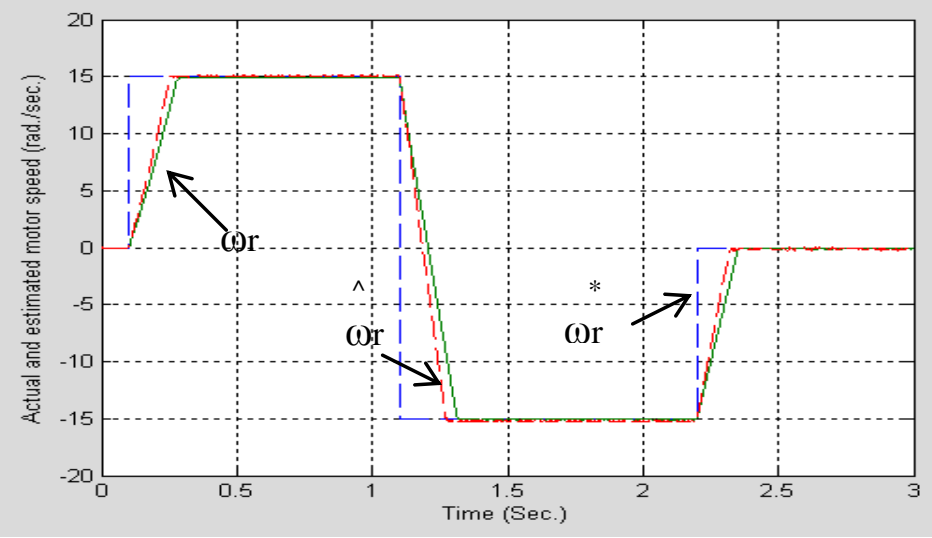

(a) Actual and estimated speed

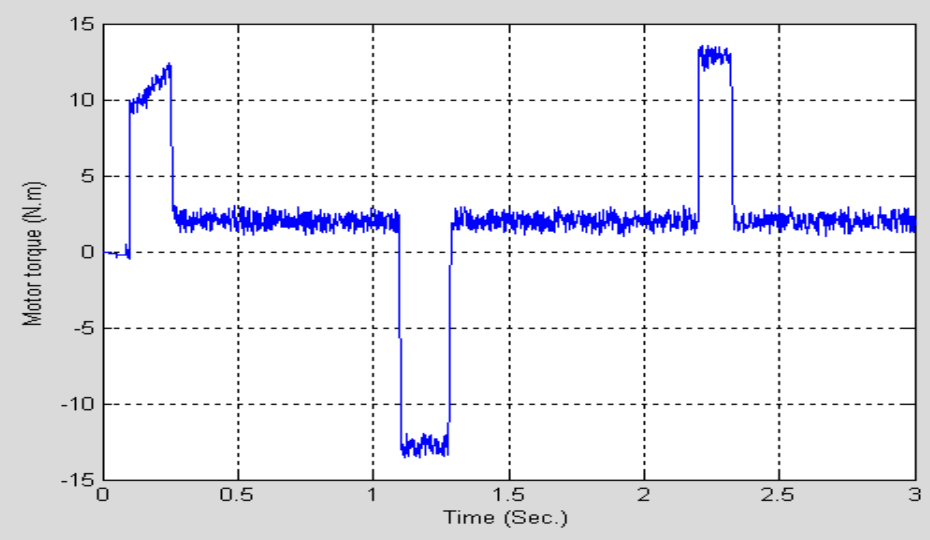

(b) Motor torque

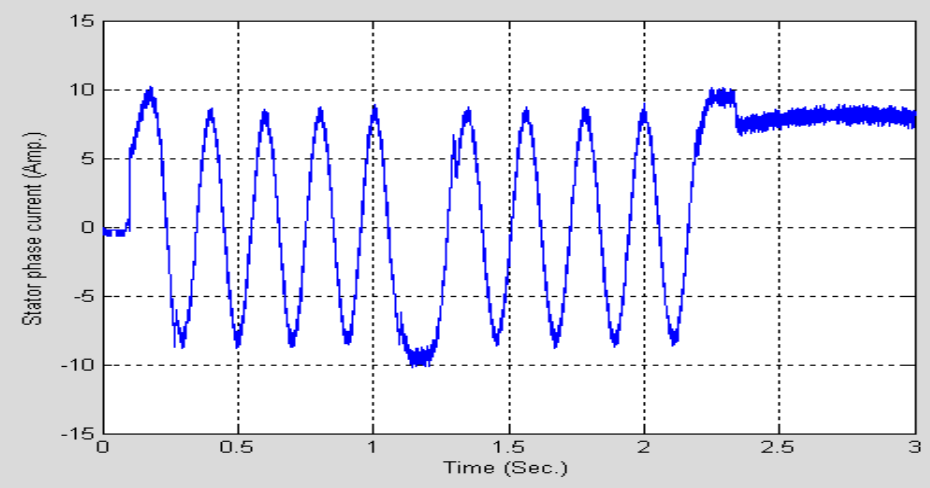

(c) Stator phase current

Figure 14: Simulation results of the forward-reverse operation using the proposed sensorless drive system 


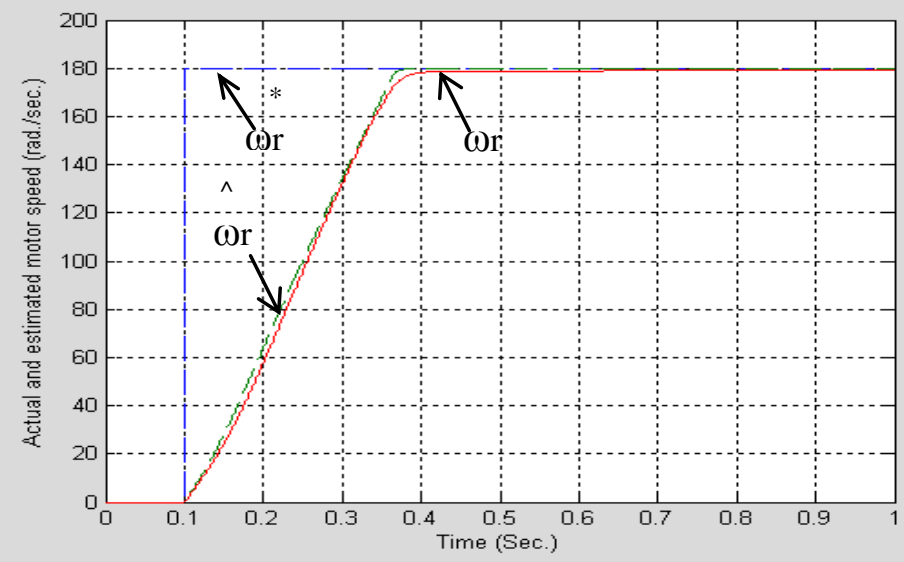

(a) Actual and estimated motor speed

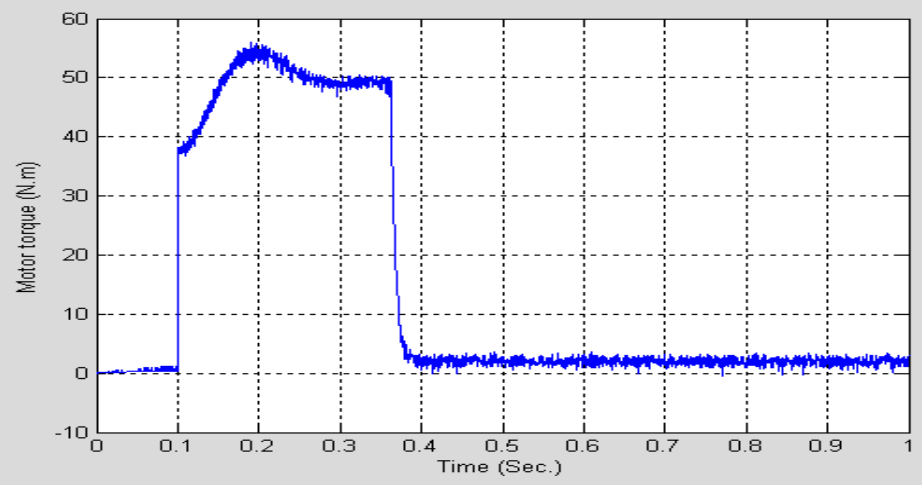

(b) Motor torque

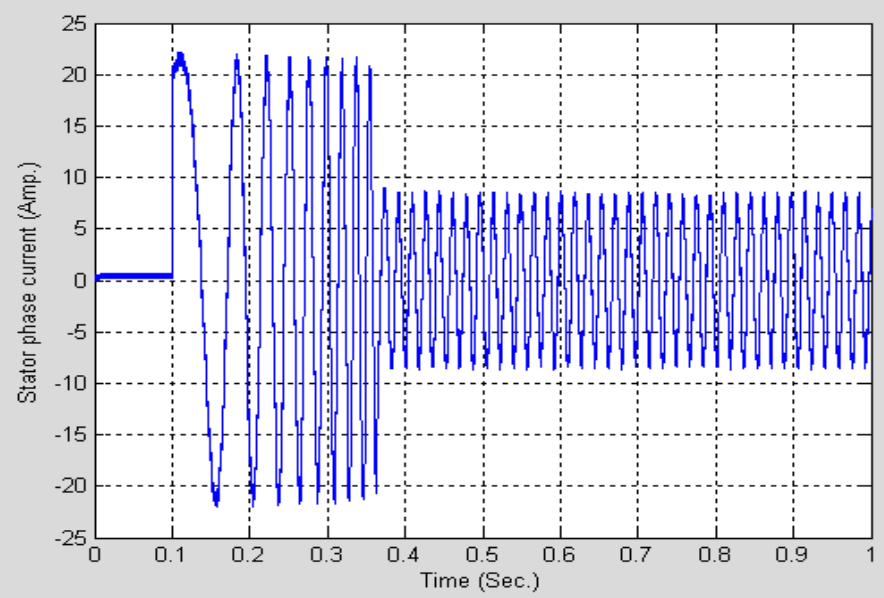

(c) Stator phase current

Figure 15: Simulation results of the acceleration operation using the proposed sensorless drive system 


\section{CONCLUSION}

This paper presents, an efficient methodology to online estimate of the basic electrical parameter set $\left(R_{s}, \sigma L_{s}, L_{s}\right.$ and $\left.T_{r}\right)$ of an induction motor using linear estimation techniques and without the measurement of motor speed. These parameters are important for high performance sensorless IFO control system. The estimation models take the form of linear regression equations which are derived from the dynamical machine model. The RLS algorithm is applied successfully for estimating the machine parameter vectors of the linear regression equations using the measurements of stator voltages, currents and estimated motor speed. The estimation is carried out by using PWM voltage waveform which is controlled from IFO control system. Thus it is possible to continuously retune the controllers of the drive as long as there are changes in the parameters. Moreover, the robust motor speed estimator based on the MRAS is proposed which uses the estimated parameters $\left(R_{s}, \sigma L_{s}\right.$ and $\left.T_{r}\right)$ to estimate the motor speed accurately for sensorless IFO control system. From the present analysis, one can draw the following main conclusions:

1- The special procedure that uses a small dc bias and a low pass filter to estimate the stator resistance has given good results.

2- The estimated parameters $\left(R_{s}, \sigma L_{s}, L_{s}\right.$ and $\left.T_{r}\right)$ have provided good performances, i.e. fast convergence time and track well their standard ones with small estimation errors.

3- The presented regression models have provided good estimation accuracy regardless of load conditions.

4- The forward-reverse operation of the drive is obtained by the robust MRAS speed estimator in guarantee the stability of the proposed sensorless control order to system at a zero speed.

5- Simulation results demonstrate that the proposed sensorless IFO control drive system is capable of working from low speed to high speed and exhibits very good dynamic and steady-state performance.

\section{REFERENCES}

[1] P. Vas, Vector control of AC Machines, a book presented by Oxford University Press, pp.122-215, 1990.

[2] R. Krishnan and F. C. Doran, "Study of parameter Sensitivity in High Performance Inverter Fed Induction Motor Drive Systems", IEEE Trans. Ind. Appl., Vol. IA-23, No.4, July/Aug., PP.623-635, 1987.

[3] P. Vas, Parameter Estimation, Condition Monitoring, and Diagnosis of Electrical Machines, Oxford Science Publications, 1993.

[4] H. A. Toliyat, E. Levi, M. Raina, "A Review of RFO Induction Motor Parameter Estimation Techniques", IEEE Trans. On Energy Conversion, Vol. 18, No. 2, pp.271-283, 2003.

[5] K. Minami, M.Veles-Reyes, D. Elten, G. C. Verghese, and D. Filbert, "MultiStage Speed and Parameter Estimation for Induction Machines", in Proc. IEEE PESC'91, 1991, pp. 596-604. 
[6] P. R. Nchez, et al., "Rotor-Resistance Estimation for Induction Machines with Indirect-Field Orientation", Control Engineering Practice, Elsevier, Vol.15, No.9, September 2007.

[7] H. B. Karayaka, M.N. Marwali, and A. Keyhani, "Induction Machines Parameter Tracking from Test Data Via PWM Inverters", in Conf. Rec. IEEE-IAS Annu. Meeting, 1997, pp.227-233.

[8] L. A. de S. Riberiro and A. M. N. Lima “ Parameter Estimation of Induction Machines Under Sinusoidal PWM Excitation", IEEE Trans. On Energy Conversion, Vol. 14, No. 4, December 1999, pp. 1218-1223.

[9] S. Moonl and A. Keyhani, "Estimation of Induction Machines Parameters from Standstill Time-Domain Data", IEEE Trans. Ind. Applicat., Vol. 30, pp.16091615, Nov./Dec. 1994.

[10] A. M. N. Lima, C. B. Jacobina, and E. B. de Souze Filho, "Nonlinear Parameter Estimation of Steady-state Induction Machine Models", IEEE Trans. Ind. Electron., Vol. 44, pp. 390-397, June 1997.

[11] G. Yang and T. H. Chin, "Adaptive-Speed Identification Scheme for a VectorControlled Speed Sensorless Inverter-Induction Motor Drive”, IEEE Trans. Ind. Applicat., vol. 29, pp. 820-825, July/Aug. 1993.

[12] H. Kubota and K. Matsuse, "Speed Sensorless Field-Oriented Control of Induction Motor with Rotor Resistance Adaptation", IEEE Trans. Ind. Applicat., Voll. 30, pp. 1219-1224, Sept./Oct. 1994.

[13] S. Suwankawin and S. Sangwongwanich, "Design Strategy of an Adaptive Full Order Observer for Speed Sensorless Induction Motor Drives Tracking Performance and Stabilization", IEEE Trans. Ind. Electr., Vol. 53, No. 1, pp. 96119, 2006.

[14] J. Al-Tayie and P. Acarnley, "Estimation of Speed, Stator Temperature and Rotor Temperature in Cage Induction Motor Drive Using the Extended Kalman Filter Algorithm", Proc. IEE-Elect. Power Applicat., Vol. 144, pp. 301-309, Sept. 1997

[15] Barut M, Bogosyan OS, Gokasan M., "Switching EKF Technique for Rotor and Stator Resistance Estimation in Speed Sensorless Control of Induction Motors" Energy Conversion and Management (Elsevier), 48 (2007):3120-3134.

[16] L. Jingchuan, X. Longya, and Z. Zhang, "An Adaptive Sliding-Mode Observer for Induction Motor sensorless Speed Control”, IEEE Trans. Ind. Applic, Vol. 41, No.4, pp. 1039-146, 2005.

[17] M.Rashed and A. F. Stronach, "A Stable Back-EMF MRAS-Based Sensorless Low Speed Induction Motor Drive Insensitive to Stator Resistance Variation", IEE Proc. Electr. Power Applic., Vol. 151, No. 6, pp. 685-693, 2004.

[18] Y. S. Mohamed, A. M. El-Sawy and A. A. Zaki, "Rotor Resistance Identification for Speed Sensorless Vector Controlled Induction Motor Drives Taking Saturation Into Account", Journal of Engineering Sciences, Assiut University, Vol. 37, No. 2, March 2009, pp. 393-412.

[19] R. H. Middeton and G. C. Goodwin, Digital Control and Estimation, Vol. 1, Prentice-Hall, Inc., Englewood Cliffs, New Jersey, First Edn., 1990.

[20] R. Blasco-Gimenez, G. Asher, M. Summer, and K. Bradley, "Dynamic Performance Limitations for MRAS Based Sensorless Induction Motor Drives. 
Part 1: Stability Analysis for the Closed Loop Drive", Proc. IEE-Elect. Power Applicat., Vol. 143, PP. 113-122, Mar. 1996.

\section{التقيم المتين لكل من السرعه والثوابث لمحرك حثى للحصول على اداء عالى من نظام التحكم للمجال الموجه}

هذا البحث يقدم طرق خطية لتقييم كل من مقاومة العضو الثابت والحث المنسرب والحث الذاتى وكذلك ثنابت الزمن لدائرة العضو الدوار لمحرك حثى. ويمثل هذا التقييم للتوابت المذكورة اهمية كبرى للحصول

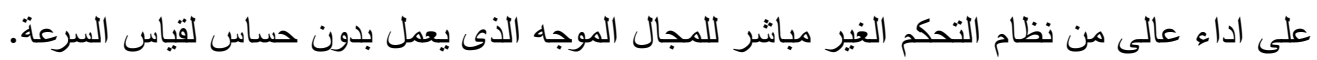

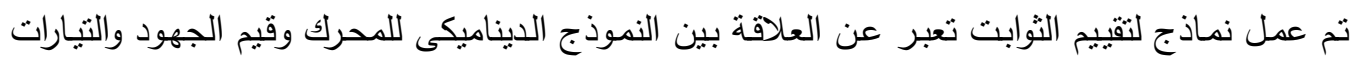

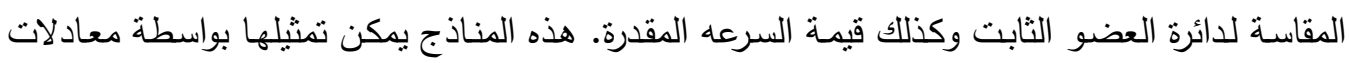

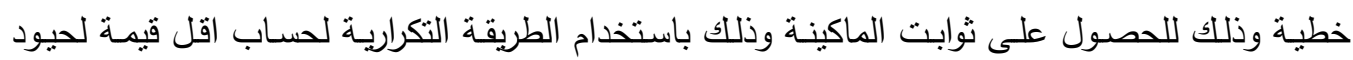
مجموع المربعات. وعلاوة على ذلك تم اقتراح مقدر متين للسرعة يعتمد على نموذج المرجعى للنظام

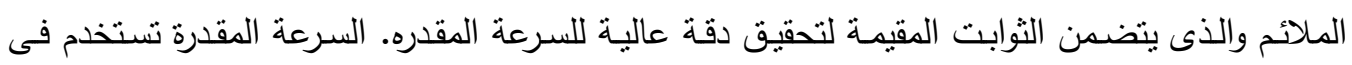

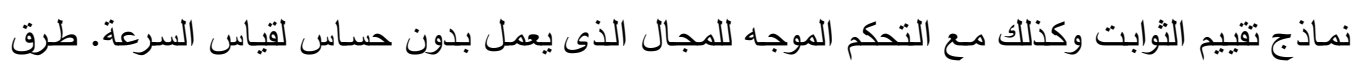

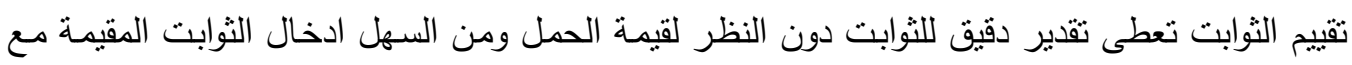

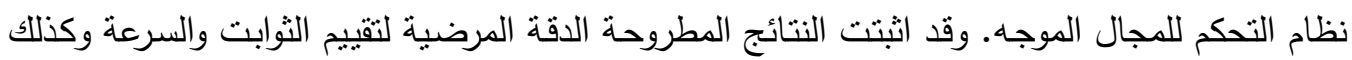
الحصول على اداء منميز للنظام المقترح. 